\title{
Twinkle-associated familial parkinsonism with Lewy pathology
}

\section{Cause or predisposition?}

David P. Breen, MBChB, PhD, David G. Munoz, MD, MSc, and Anthony E. Lang, MD

Neurolog ${ }^{\circledR}$ 2020;95:644-647. doi:10.1212/WNL.0000000000010674

Mitochondrial dysfunction is a recognized cause of autosomal recessive Parkinson disease (PD) and may contribute to idiopathic disease. ${ }^{1}$ Twinkle protein is a DNA helicase coded by the C10orf 2 gene, which, along with polymerase gamma and other proteins, is responsible for regulating mitochondrial replication. Heterozygous C10orf2 mutations are a recognized cause of chronic progressive ophthalmoplegia (CPEO) and other neurologic manifestations, but their relationship with parkinsonism is unclear. Here, we report a case (along with postmortem examination findings) of familial parkinsonism associated with a heterozygous mutation in C10orf2, alongside reviewing previously published cases.

\section{Case report}

A 61-year-old man was referred to our clinic with an 18-month history of left leg dragging and left arm motor dysfunction (e.g., difficulty putting hand in pocket). Family members commented that he had a softer voice and reduced facial expression. Nonfatigable bilateral eyelid ptosis was present on his driving license 3 years earlier. His mother had been diagnosed with PD: she presented with shuffling gait and poor balance in her early 60 s, responded well to levodopa but developed peak-dose dyskinesias, and died aged 79 years.

Examination confirmed bilateral ptosis (palpebral fissures $8 \mathrm{~mm}$ vertically and normal levator excursion) and a mild complex ophthalmoplegia. There was evidence of parkinsonism (predominantly affecting the left hemibody), which improved with levodopa (Video).

MR brain scan showed patchy small vessel ischemic changes in the pons but no other abnormalities. Single-fiber electromyogram was abnormal with a mean jitter duration $47 \mathrm{mi}$ croseconds (normal <36). Acetylcholine receptor antibodies were negative. POLG testing revealed no pathogenic mutations. Muscle biopsy was booked, but the patient did not attend. A provisional diagnosis of PD with CPEO was made, although the possibility of a unifying etiology related to mitochondrial dysfunction was considered.

Over the next few years, additional medications (selegiline, entacapone, and pramipexole) were sequentially added due to the development of motor fluctuations including mild generalized dyskinesias. Around 7 years after diagnosis, he began to develop nonmotor complications including cognitive decline, falls (ultimately requiring a walking frame), neuropsychiatric symptoms (visual hallucinations and paranoia), and swallowing difficulties. These progressively worsened despite medication alterations (pramipexole and

\author{
Correspondence \\ Dr. Lang \\ Anthony.Lang@ \\ uhnresearch.ca
}

MORE ONLINE

- Video

From the Centre for Clinical Brain Sciences (D.P.B.), University of Edinburgh; Anne Rowling Regenerative Neurology Clinic (D.P.B.), University of Edinburgh; Usher Institute of Population Health Sciences and Informatics (D.P.B.), University of Edinburgh, Scotland; Department of Laboratory Medicine (D.G.M.), St Michael's Hospital, Toronto, Canada; Edmond J. Safra Program in Parkinson's Disease and the Morton and Gloria Shulman Movement Disorders Clinic (A.E.L.), Toronto Western Hospital; Department of Medicine (A.E.L.), University of Toronto; and Krembil Research Institute (A.E.L.), Toronto Western Hospital, Ontario, Canada.

Go to Neurology.org/N for full disclosures. Funding information and disclosures deemed relevant by the authors, if any, are provided at the end of the article. 


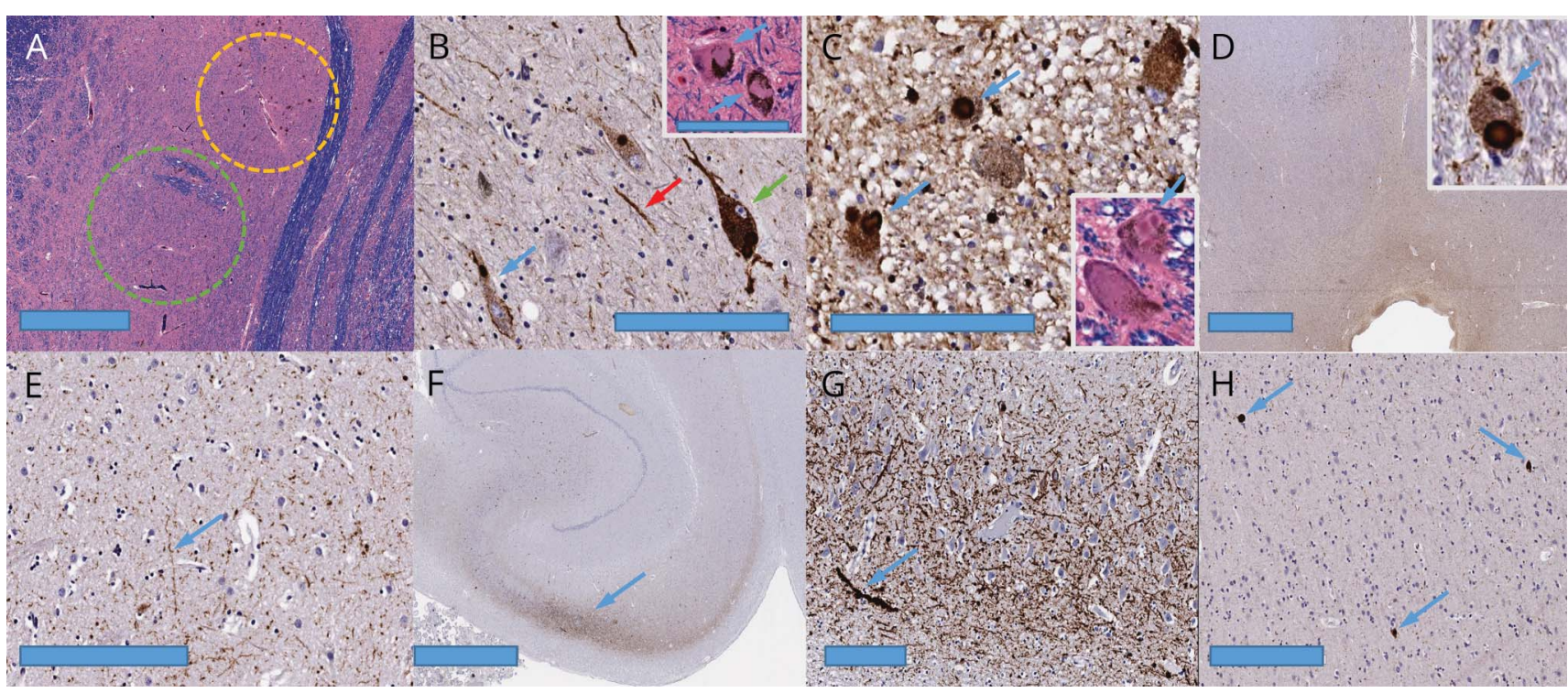

(A) Low-power view of the substantia nigra showing patchy loss of neurons, with areas of complete loss (green circle) contrasting with others of partial preservation (yellow circle), bar 800 um. Luxol fast blue (LFB) staining on hematoxylin and eosin. (B) Substantia nigra immunostained for alpha-synuclein showing Lewy bodies (blue arrows), Lewy neurites (red arrow), and neurons with cytoplasm diffusely filled with alpha-synuclein (green arrow), bar $200 \mu \mathrm{m}$. The inset shows Lewy bodies (blue arrows) in 2 neurons on LFB staining, bar $100 \mu \mathrm{m}$ (applies to all insets). (C) Locus coeruleus immunostained for alpha-synuclein, showing labeled neurons with Lewy bodies (blue arrows), bar $200 \mu \mathrm{m}$. The inset shows Lewy bodies on LFB staining (blue arrows). (D) Periaqueductal gray (aqueduct at center bottom) immunostained for alpha-synuclein showing labeled neurons with Lewy bodies (inset, blue arrow), bar 2 mm. (E) Putamen immunostained for alphasynuclein showing Lewy neurites (blue arrow), bar $200 \mu \mathrm{m}$. (F) Hippocampus immunostained for alpha-synuclein showing labeling in the CA2 sector (blue arrow), bar $2.5 \mathrm{~mm}$. (G) Higher power view of the alpha-synuclein immunostained CA2 area of the hippocampus showing predominantly horizontally oriented Lewy neurites (blue arrow), bar $200 \mu \mathrm{m}$. (H) Temporal neocortex immunostained for alpha-synuclein showing scattered cortical Lewy bodies (blue arrows), bar $200 \mu \mathrm{m}$.

selegiline stopped; rivastigmine and quetiapine started). He was eventually admitted to a nursing home and died approximately 10 years after diagnosis due to a presumed aspiration pneumonia.
Just before his death, further genetic testing revealed a heterozygous variant in the C10orf2 gene on chromosome 10 (c.908 G>A, p.[Arg303Gln]). Bioinformatic analysis predicted that this variant was pathogenic and had a very low

Table Previously reported cases of parkinsonism associated with heterozygous C10orf2 mutations

\begin{tabular}{|c|c|c|c|c|c|c|c|c|}
\hline $\begin{array}{l}\text { Ref/ } \\
\text { case }\end{array}$ & Sex & Onset $^{\mathrm{a}}$ & $\begin{array}{l}\text { Family } \\
\text { history }\end{array}$ & MR scan & DAT scan & $\begin{array}{l}\text { Muscle } \\
\text { biopsy }\end{array}$ & $\begin{array}{l}\text { Levodopa } \\
\text { response }\end{array}$ & Mutation \\
\hline $3 / I I I-3$ & $\mathrm{~F}$ & Early 50s & Yes & NR & NR & NR & NR & R374Q \\
\hline $3 / I I I-2$ & $\mathrm{~F}$ & 41 & Yes & Normal & NR & Abnormal & Yes & R374Q \\
\hline 3/III-4 & $\mathrm{F}$ & Early $40 \mathrm{~s}$ & Yes & NR & NR & NR & Yes & R374Q \\
\hline $4 /$ & $\mathrm{F}$ & 57 & Yes & Lacunar infarct in basal ganglia & NR & NR & No & A475T \\
\hline 5/III-1 & M & 50 & Yes & Normal & Abnormal & Normal & Not treated & R334Q \\
\hline $6 /$ & M & 70 & No & $\begin{array}{l}\text { Nonspecific white matter } \\
\text { lesions }\end{array}$ & Abnormal & Abnormal & Not treated & АЗЗ3Т \\
\hline 7/II-2 & $\mathrm{F}$ & Early $80 \mathrm{~s}$ & Yes & Mild white matter changes & Abnormal & NR & Yes & G1750A \\
\hline 7/II-3 & $\mathrm{F}$ & 77 & Yes & NR & Abnormal & Abnormal & Not treated & G1750A \\
\hline
\end{tabular}

Abbreviations: DAT = dopamine transporter; NR = not reported.

All cases had CPEO, which began 1-2 decades before their parkinsonism (3 cases underwent corrective eye surgery), with 1 exception where the patient had childhood-onset ptosis. Similar numbers of males and females were affected, and the majority had a positive family history. Dopamine transporter imaging was universally abnormal when it was performed, whereas 3 of 5 MR brain scans showed white matter abnormalities. Muscle biopsy tended to be abnormal when it was performed (with mitochondrial changes including COX negative fibers and mtDNA deletions), but 1 was normal. Most patients responded to levodopa when it was initiated, although limited information was available on progression of symptoms. Brain postmortem assessment was not performed in any of these cases. ${ }^{a}$ Age at onset of parkinsonism.

${ }^{\mathrm{b}}$ One of more first-degree family member. 
allele frequency on gnomAD (0.0012\%). PD gene panel testing identified no other clinically relevant variants.

Postmortem examination revealed severe, patchy neuronal cell loss in the substantia nigra with evidence of limbic (transitional) stage Lewy body disease according to the Montine classification (figure). ${ }^{2}$ In the substantia nigra, alpha-synuclein immunostains labeled Lewy bodies and Lewy neurites, as well as diffusely filled perikarya. Lewy bodies were also present in the locus coeruleus, periaqueductal gray matter, basal temporal neocortex, and cingulate gyrus (figure, $\mathrm{C}, \mathrm{D}, \mathrm{H}$ ); but sparse in other regions of the neocortex. There were no abnormalities in the cerebellum. There was no significant deposition of tau, betaamyloid, or TDP-43 proteins.

\section{Discussion}

We propose that heterozygous C10orf2 mutations may be a rare cause of parkinsonism and should be considered in patients with a positive family history and/or other features of a mitochondrial disorder (e.g., CPEO). We searched the literature and found 8 previously reported cases of parkinsonism associated with heterozygous C10orf2 mutations (table). ${ }^{3-7}$ They are unlikely to be a major contributor to overall PD heritable risk; indeed, C10orf2 does not appear as a risk loci on the most recent meta-analysis of genome-wide association studies. ${ }^{8}$

We cannot exclude the possibility that the association may be a coincidence, especially because we were unable to perform segregation analysis. Unfortunately, only fixed brain tissue was available for the postmortem examination, which precluded molecular analysis (such as mtDNA deletion load). In the single reported autopsy case of a patient with heterozygous C10orf2 mutation, there was also significant loss of substantia nigra neurons (although the patient did not have clinical evidence of parkinsonism), but no Lewy bodies were present (unlike our case). ${ }^{9}$ We hope that neuropathologic analysis of future cases will help to determine the precise pathologic underpinnings of parkinsonism in heterozygous C10orf2 mutation carriers.

Twinkle protein is important for maintaining mtDNA integrity. In a mouse model expressing mutant Twinkle, there was accelerated accumulation of mtDNA deletions and loss of TH-positive neurons (leading to motor impairment). ${ }^{10}$ Patients with biallelic C10orf2 mutations typically present with severe and complex neurologic phenotypes (e.g., infantile-onset spinocerebellar ataxia, epilepsy, sensory polyneuropathy, Perrault syndrome, and adult-onset mitochondrial myopathy) alongside systemic features, but not parkinsonism. The classical pathology in these patients includes severe neuronal loss in the substantia nigra in the absence of Lewy bodies or alpha-synuclein deposition, often accompanied by degeneration of the cerebellar-dentato-olivary system. Further studies are required to explain why most patients with biallelic C10orf2 mutations do not exhibit parkinsonism despite demonstrating severe substantia nigra neuronal loss (which also occurs with biallelic POLG mutations). ${ }^{9}$
Heterogeneous neuropathology is a recognized feature of genetic PD associated with mitochondrial dysfunction. A review of autopsy findings in 18 homozygous or compound heterozygous Parkin cases found Lewy bodies in only 6 patients, despite evidence of neuronal loss in the substantia nigra in all cases. ${ }^{11}$ In the 2 postmortem cases of biallelic PINK1 mutations, Lewy bodies were present in one ${ }^{12}$ and absent in the other. ${ }^{13}$ The role of heterozygous Parkin and PINK1 mutations is controversial; however, it is intriguing that the limited number of autopsy studies has shown diffuse Lewy bodies in both groups. This may support the concept of genetic predisposition to PD by the mitochondrial dysfunction caused by these heterozygous states, which is in line with a recent report showing greater Lewy body pathology in older patients with mitochondrial dysfunction due to a range of nuclear and mtDNA genetic defects. ${ }^{14}$

\section{Acknowledgment}

The authors are grateful to Prof. Robert Taylor, Dr. Nichola Lax, and Dr. Grainne Gorman (Wellcome Centre for Mitochondrial Research, Newcastle University, UK) for their advice on assessment of mitochondrial pathology in postmortem brain samples during preparation of this manuscript. D.P. Breen is supported by a Wellcome Clinical Research Career Development Fellowship (214571/Z/18/Z).

\section{Study funding}

No targeted funding reported.

\section{Disclosure}

The authors report no disclosures relevant to the manuscript. Go to Neurology.org/N for full disclosures.

\section{Publication history}

Received by Neurology April 9, 2020. Accepted in final form July 15, 2020.

Appendix Authors

\begin{tabular}{lll}
\hline Name & Location & Contribution \\
\hline $\begin{array}{l}\text { David P. } \\
\text { Breen, } \\
\text { MBChB, PhD }\end{array}$ & $\begin{array}{l}\text { University of } \\
\text { Edinburgh, } \\
\text { Edinburgh, Scotland }\end{array}$ & Wrote the paper \\
\hline $\begin{array}{l}\text { David G. } \\
\text { Munoz, MD, } \\
\text { MSc }\end{array}$ & $\begin{array}{l}\text { St Michael's Hospital, } \\
\text { Toronto, Canada }\end{array}$ & $\begin{array}{l}\text { Interpreted the postmortem } \\
\text { brain examination and wrote } \\
\text { the paper }\end{array}$ \\
\hline $\begin{array}{l}\text { Anthony E. } \\
\text { Lang, MD }\end{array}$ & $\begin{array}{l}\text { Toronto Western } \\
\text { Hospital, Toronto, } \\
\text { Canada }\end{array}$ & $\begin{array}{l}\text { Managed the patient } \\
\text { throughout his life and wrote } \\
\text { the paper }\end{array}$ \\
\hline
\end{tabular}

\section{References}

1. Bender A, Krishnan KJ, Morris CM, et al. High levels of mitochondrial DNA deletions in substantia nigra neurons in aging and Parkinson disease. Nat Genet 2006;38:515-517.

2. Montine TJ, Phelps $\mathrm{CH}$, Beach TG, et al. National Institute on Aging-Alzheimer's Association guidelines for the neuropathologic assessment of Alzheimer's disease: a practical approach. Acta Neuropathol 2012;123:1-11.

3. Baloh RH, Salavaggione E, Milbrandt J, Pestronk A. Familial Parkinsonism and ophthalmoplegia from a mutation in the mitochondrial DNA helicase Twinkle. Arch Neurol 2007;64:998-1000. 
4. Liu Z, Ding Y, Du A, et al. A novel Twinkle (PEO1) gene mutation in a Chinese family with adPEO. Mol Vis 2008; 14:1995-2001.

5. Vandenberghe W, van Laere K, Debruyne F, et al. Neurodegenerative parkinsonism and progressive external ophthalmoplegia with a Twinkle mutation. Mov Disord 2009;24:308-309.

6. Brandon BR, Diederich NJ, Soni M, et al. Autosomal dominant mutations in POLG and C10orf2: association with late onset chronic progressive ophthalmoplegia and Parkinsonism in two patients. J Neurol 2013;260:1931-1933.

7. Kiferle L, Orsucci D, Mancuso M, et al. Twinkle mutation in an Italian family with external progressive ophthalmoplegia and parkinsonism: a case report and an update on the state of the art. Neurosci Lett 2013;556:1-4.

8. Nalls MA, Blauwendraat C, Vallerga CL, et al. Identification of novel risk loci, causal insights, and heritable risk for Parkinson's disease: a meta-analysis of genome-wide association studies. Lancet Neurol 2019;18:1091-1102.
9. Palin EJH, Paetau A, Suomalainen A. Mesencephalic complex I deficiency does not correlate with parkinsonism in mitochondrial DNA maintenance disorders. Brain 2013;136:2379-2392.

10. Song L, Shan Y, Lloyd KCK, Cortopassi GA. Mutant Twinkle increases dopaminergic neurodegeneration, mtDNA deletions and modulates Parkin expression. Hum Mol Genet 2012;21:5147-5158.

11. Schneider SA, Alcalay RN. Neuropathology of genetic synucleinopathies with parkinsonism: review of the literature. Mov Disord 2017;32:1504-1523.

12. Samaranah L, Lorenzo-Betancor O, Arbelo JM, et al. PINK1-linked parkinsonism is associated with Lewy body pathology. Brain 2010;133:1128-1142.

13. Takanashi M, Li Y, Hattori N. Absence of Lewy pathology associated with PINK1 homozygous mutation. Neurology 2016;86:2212-2213.

14. Erskine D, Reeve AK, Polikoski T, et al. Lewy body pathology is more prevalent in older individuals with mitochondrial disease than controls. Acta Neuropathologica 2020;139:219-221.

\section{COVID-19 and Neurologic Disease: Call for Papers!}

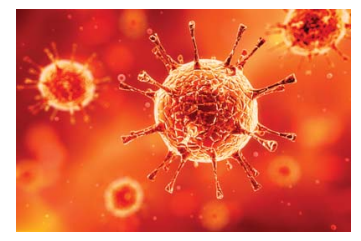

The editors of Neurology are interested in papers that address the neurological aspects of COVID-19 infection and challenges to the management of patients with chronic neurological conditions who have, or are at risk for, the infection. Relevant papers that pass initial internal review will undergo expedited peer review and online publication. We will consider papers posted in preprint servers.

Submit observational studies and clinical trials as Articles and case series and case reports under the Clinical/Scientific Notes category to https://submit.neurology.org/ today!

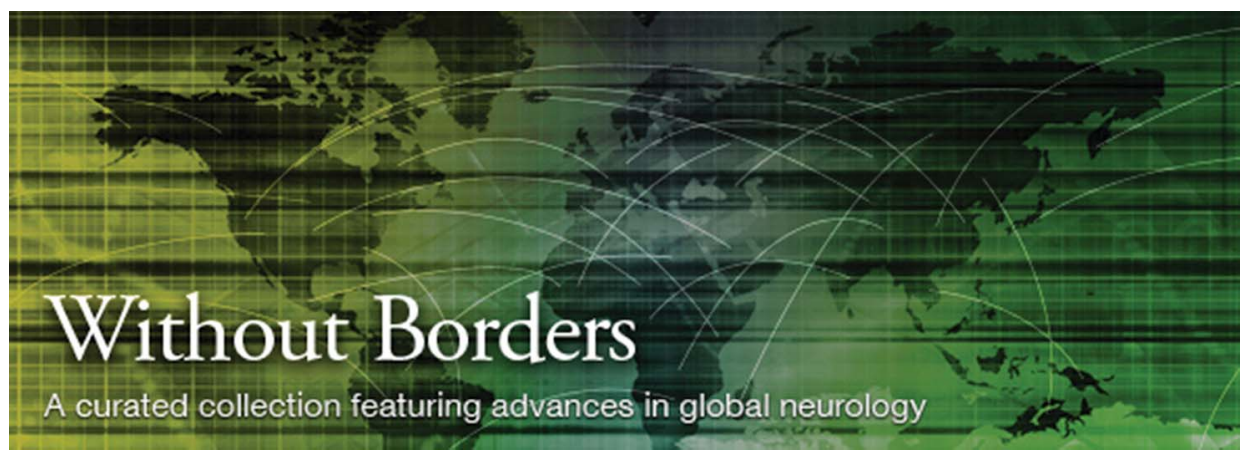

\section{Without Borders - A curated collection featuring advances in global neurology}

This Neurology ${ }^{\circledR}$ special interest website is the go-to source for tracking science and politics of neurology beyond the United States, featuring up-to-the-minute blogs, scholarly perspectives, and academic review of developments and research from Neurology journals and other sources. Curated by Gretchen L. Birbeck, MD, MPH.

Expand your world view at Neurology.org/woborders. 


\title{
Neurology
}

\author{
Twinkle-associated familial parkinsonism with Lewy pathology: Cause or \\ predisposition? \\ David P. Breen, David G. Munoz and Anthony E. Lang
}

Neurology 2020;95;644-647 Published Online before print August 26, 2020

DOI 10.1212/WNL.0000000000010674

This information is current as of August 26, 2020

\section{Updated Information \&} Services

References

Subspecialty Collections

Permissions \& Licensing

Reprints including high resolution figures, can be found at: http://n.neurology.org/content/95/14/644.full

This article cites 14 articles, 1 of which you can access for free at: http://n.neurology.org/content/95/14/644.full\#ref-list-1

This article, along with others on similar topics, appears in the following collection(s):

\section{Mitochondrial disorders}

http://n.neurology.org/cgi/collection/mitochondrial_disorders Parkinson's disease/Parkinsonism

http://n.neurology.org/cgi/collection/parkinsons_disease_parkinsonism

Information about reproducing this article in parts (figures,tables) or in its entirety can be found online at:

http://www.neurology.org/about/about_the_journal\#permissions

Information about ordering reprints can be found online:

http://n.neurology.org/subscribers/advertise

Neurology ${ }^{\circledR}$ is the official journal of the American Academy of Neurology. Published continuously since 1951, it is now a weekly with 48 issues per year. Copyright Copyright ( 2020 The Author(s). Published by Wolters Kluwer Health, Inc. on behalf of the American Academy of Neurology.. All rights reserved. Print ISSN: 0028-3878. Online ISSN: 1526-632X.

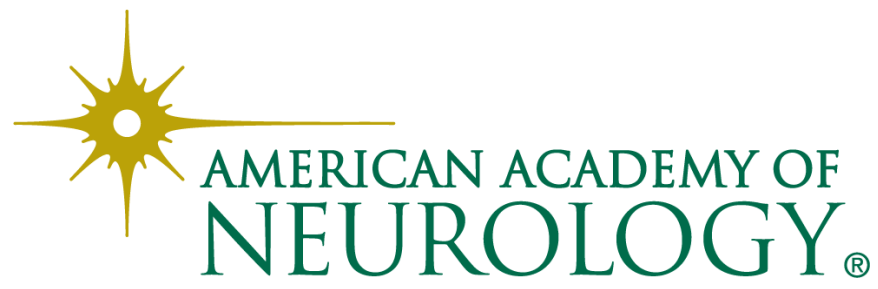

